\title{
A 150-year record of human impact in the Lake Wuliangsu (China) watershed: evidence from polycyclic aromatic hydrocarbon and organochlorine pesticide distributions in sediments
}

\author{
Beibei SHEN, ${ }^{1,2}$ Jinglu WU, ${ }^{1 *}$ Zhonghua ZHAO $^{1}$
}

${ }^{1}$ State Key Laboratory of Lake and Environmental Sciences, Nanjing Institute of Geography and Limnology, Chinese Academy of Sciences, Nanjing 210008; ${ }^{2}$ University of Chinese Academy of Sciences, Beijing 100049, China

*Corresponding author: w.jinglu@niglas.ac.cn

\begin{abstract}
Human activities in and around Lake Wuliangsu, in the upper reaches of the Yellow River, triggered environmental changes for which evidence is preserved in the lake sediments. We investigated the past 150 years of human impacts on Lake Wuliangsu using high-resolution records of polycyclic aromatic hydrocarbons (PAHs) and organochlorine pesticides (OCPs) in the sediments. Prior to the 1950s, there were very low concentrations of contaminants in the lake deposits. In the 1950s, relatively higher OCP concentrations and proportions of low molecular weight (LMW) PAHs were related to the intensification of agricultural activity. Since the 1990s, increases in high molecular weight (HMW) PAH concentrations and their proportions, and decreases in OCP concentrations and proportions of LMW PAHs, indicated human impacts on the lake were dominated by industry and urban development. Thus, there have been three periods of human-mediated environmental change in the Lake Wuliangsu basin, inferred from the PAH and OCP records (pre-1950s, 1950s-1990s, and 1990s to present). The inferred changes are consistent with the local socioeconomic data. The agreement between paleolimnologic records from Lake Wuliangsu and socioeconomic data suggests that the lake sediments provide a reliable archive for investigating the environmental history of human impacts on the lake.
\end{abstract}

Key words: Polycyclic aromatic hydrocarbons; organochlorine pesticides; human impacts; sediment record; Lake Wuliangsu; China.

Received: June 2016. Accepted: September 2016.

\section{INTRODUCTION}

Rapid economic and social development in China over the last few decades resulted in increasing environmental contamination. Among the contaminants, polycyclic aromatic hydrocarbons (PAHs) and organochlorine pesticides (OCPs) have aroused growing concern because they seriously threaten human health and the environment and are concurrently recalcitrant to degradation, accumulate in human and animal tissue, biomagnify along food chains, and undergo long-range atmospheric transport making them ubiquitous distribution in the global environment, even the areas located far from human activities such as the Polar Regions (Schmid et al., 2010). For example, PAHs mainly derive from incomplete burning of fuels, garbage, or organic substances such as tobacco and other plant materials (Kim et al., 2013); OCPs were mainly used as insecticides, herbicides and fungicides in agriculture. Eventually, PAHs and OCPs can be deposited in lake sediments because of their strong affinity to particles. Consequently, an examination of the depositional history of PAHs and OCPs in a lake, related to different anthropogenic sources, can be used to infer past human activities.
Previous studies on sedimentary PAH and OCP profiles revealed that PAHs display strong correlations with local socioeconomic factors, such as energy consumption, industrialization, and human population growth (Liu et al., 2005; Wilcke, 2007; Liu et al., 2012; Machado et al., 2014), and the vertical distribution of OCPs in the sediment is related to their historical production and use (Zhang et al., 2002; Liu et al., 2009; Bigus et al., 2014). Therefore, analysis of PAHs and OCPs in a sediment core can enable reconstruction of the history of regional industrial, urban and agricultural activities.

Lakes in arid and semi-arid regions are sensitive ecosystems and quickly respond to natural or human-induced changes in the watershed. In such regions, lake sediment records are one of the most easily accessed natural archives that can be used to interpret human-induced environmental changes, given that different anthropogenic activities leave distinct contaminants in the sediment. The Lake Wuliangsu wetland, situated in a semi-arid region, is the largest lake system in the Yellow River Valley. Owing to its extremely high biodiversity, the Lake Wuliangsu wetland was included in the Convention on Wetlands of International Importance in 1979. However, the area is also the most important food 
base of the Inner Mongolia Autonomous Region, and local residents have engaged in increasingly intensive agricultural activities since the beginning of the $20^{\text {th }}$ century. Coupled with rapid industrialization and urbanization in the last few decades, large amounts of agricultural, municipal and industrial pollutants have been discharged into the lake, and now constitute a major threat to the aquatic environment. To fully understand the current state and future trajectory of the lake, it requires knowledge of past human-mediated environmental changes, which can be achieved through study of lake sediment cores. Previous studies of Lake Wuliangsu used sediment cores to investigate the history of lacustrine trophic state changes (Lü et al., 2008; Wu et al., 2013), ecological dynamics (He et al., 2015) and heavy metal contamination (Ma et al., 2013). In this study, we examined the vertical profile of PAHs and OCPs in a sediment core from Lake Wuliangsu to better understand anthropogenically driven environmental changes in the lake though time. Results of this study will provide information to formulate management strategies for the lake and its watershed.

\section{METHODS}

\section{Study site and sampling}

Lake Wuliangsu $\left(40^{\circ} 47^{\prime}-41^{\circ} 03^{\prime} \mathrm{N}, 108^{\circ} 43^{\prime}-108^{\circ} 57^{\prime} \mathrm{E}\right)$ is located in Bayan Nur, Inner Mongolia, China (Fig. 1). It has a surface area of $306 \mathrm{~km}^{2}$, volume of $2.6 \times 10^{8} \mathrm{~m}^{3}$ and maximum depth of $2.67 \mathrm{~m}$ (average $0.86 \mathrm{~m}$ ) (Wu et al., 2013). The catchment of Lake Wuliangsu, known as the Hetao Irrigation District, covers a surface area of $1.12 \times 10^{4} \mathrm{~km}^{2}$, and is one of the three largest irrigation areas in China. The total population of the lake region is approximately 1.67 million, with nearly 0.6 million people living in the city and county, and 1.07 million engaged in livestock activities and agriculture. Within the lake catchment, agriculture, aquaculture, urbanization and industrialization have expanded rapidly in recent years (Ma et al., 2013). The lake receives most of its water input from agricultural irrigation, which originates from the Yellow River and is transported by the main irrigation ditch through the Hetao Irrigation District. The lake water returns to the Yellow River via the lake's south outlet (Wu et al., 2013). Municipal sewage and industrial wastewater also flow into the lake. As a consequence, nutrients and pollutants (e.g., heavy metals, organic residues) enter the lake and accumulate in the sediments, causing environmental problems.

In August 2008, a continuous and undisturbed core was taken from the deepest area of Lake Wuliangsu using a gravity corer (Fig. 1). The core was sub-sampled at 1$\mathrm{cm}$ intervals and preserved at $-20^{\circ} \mathrm{C}$ prior to analysis.

\section{Extraction and instrumental analyses}

Freeze-dried, homogenized samples (5g dry weight) were extracted using dichloromethane by accelerated solvent extraction (ASE-100, Dionex, Sunnyvale, CA, USA). Sulfur was removed by addition of activated copper. The extracts were concentrated with a rotary evaporator (Büchi R-200; Flawil, Switzerland), and solvent-exchanged to hexane. The extracts collected were purified using an alumina/silica gel $(1: 2 \mathrm{v} / \mathrm{v})$ chromatography column. The column was eluted with $70-\mathrm{mL} n$ hexane/ dichloromethane $(5: 2 \mathrm{v} / \mathrm{v})$. The elution was evaporated and concentrated to $1 \mathrm{~mL}$ under a gentle stream of nitrogen.

OCPs were quantified and included dichlorodiphenyltrichloroethane (DDTs, including $p, p^{\prime}$-DDT, $p, p^{\prime}$-DDD and $p, p^{\prime}$-DDE), hexachlorocyclohexanes (HCHs, including $\alpha-, \beta-, \gamma$ - and $\delta-\mathrm{HCH}$ ), chlordanes (including $\alpha$-chlordane, $\gamma$-chlordane, heptachlor and heptachlor epoxide), aldrins (including aldrin, dieldrin, endrin, endrin aldehyde, endrin ketone), endosulfans (including $\alpha$-endosulfan, $\beta$-endosulfan, endosulfan sulfate) and methoxychlor. Sixteen priority PAHs, proposed by the US Environmental Protection Agency, were quantified and included naphthalene (Nap), acenaphthylene (Acy), acenaphthene (Ace), fluorene ( $\mathrm{Fl}$ ), phenanthrene (Phe), anthracene (Ant), fluoranthene (Flu), pyrene (Pyr), benzo(a)anthracene $(\mathrm{BaA})$, chrysene $(\mathrm{Chr})$, benzo(b)fluoranthene $(\mathrm{BbF})$, benzo(k)fluoranthene $(\mathrm{BkF})$, benzo(a)pyrene (BaP), indeno(1,2,3-cd)pyrene (IcdP), dibenzo(ah)anthrathene (DahA), and benzo(ghi)perylene (BghiP).

Quantitative determination of OCPs was performed using an Agilent 7890 gas chromatograph equipped with a ${ }^{63} \mathrm{Ni} \mu$-electron capture detector (GC-ECD) and a DB$5 \mathrm{MS}$ fused silica capillary column $(30 \mathrm{~m} \times 250 \mu \mathrm{m} \times 0.25$ $\mu \mathrm{m})$. Oven temperatures were programmed from 60 to $170^{\circ} \mathrm{C}$ at a rate of $10^{\circ} \mathrm{C} \mathrm{min}^{-1}(2 \mathrm{~min}$ hold $)$, to $280^{\circ} \mathrm{C}$ at a rate of $5^{\circ} \mathrm{C} \mathrm{min}^{-1}$ ( $3 \mathrm{~min}$ hold), and then to $300^{\circ} \mathrm{C}$ at a rate of $15^{\circ} \mathrm{C} \mathrm{min}^{-1}$. The determination of PAHs was performed on a high-performance liquid chromatograph (HPLC) (Agilent 1200 HPLC) equipped with diode array detection (DAD), coupled with a fluorescence detector (FLD). The separation column was a WATERS PAHs C18 $(4.6 \mathrm{~mm} \times$ $250 \mu \mathrm{m}$, particle size: $5 \mu \mathrm{m}$ ). The mobile phase was a gradient of acetonitrile and purified water $(60 \%$ acetonitrile at first; after $20 \mathrm{~min}$, linear gradient to $100 \%$ acetonitrile

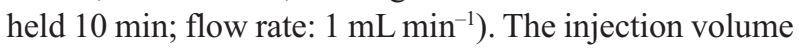
was $20 \mu \mathrm{L}$.

\section{Quality control and quality assurance}

All data were subject to strict quality control procedures. Method detection limits (MDLs) were in the range of 0.01-2.81 $\mathrm{ng} \mathrm{g}^{-1}$ for OCPs and 0.03-3.57 $\mathrm{ng} \mathrm{g}^{-1}$ for PAHs. Analytical results lower than MDLs were reported 
as not detectable (ND) and zero was assigned for statistical purposes. The spiked recoveries of the sample matrix ranged from $68 \%$ to $112 \%$ for OCPs and $76 \%$ to $103 \%$ for PAHs. Procedural blanks were performed periodically to prevent contamination. All analyses are reported on a dry weight basis.

\section{Sediment elemental analysis and radiometric dating}

Concentrations of heavy metals, total organic carbon (TOC) and total nitrogen (TN) and the core chronology were described in Ma et al. (2013) and Wu et al. (2013). Briefly, the heavy metals were determined using an American Leeman Labs Profile Inductively Coupled PlasmaAtomic Emission Spectrometer (ICP-AES), after digestion with nitrichydrofluoric-perchloric acid. Data quality was ensured through the use of duplicates, blanks and standard reference materials. TOC and TN were measured with a CE-440 (EAI Company) elemental analyzer; ${ }^{210} \mathrm{~Pb}$ and ${ }^{137} \mathrm{Cs}$ analyses of freeze-dried sediment were performed by direct gamma spectrometry using an Ortec HPGe GWL series, well-type, coaxial, low background intrinsic germanium detector. The absolute efficiencies of the detectors were determined using calibrated sources and sediment samples of known ${ }^{210} \mathrm{~Pb}$ activity. Corrections were made for the effect of self-absorption of low energy $\gamma$-rays within the sample.

\section{Statistical analysis}

The constrained incremental sum of squares cluster analysis (CONISS) was performed using the program PAST version 3.01 (Hammer et al., 2001) to identify statistically different zones in the sediment core.

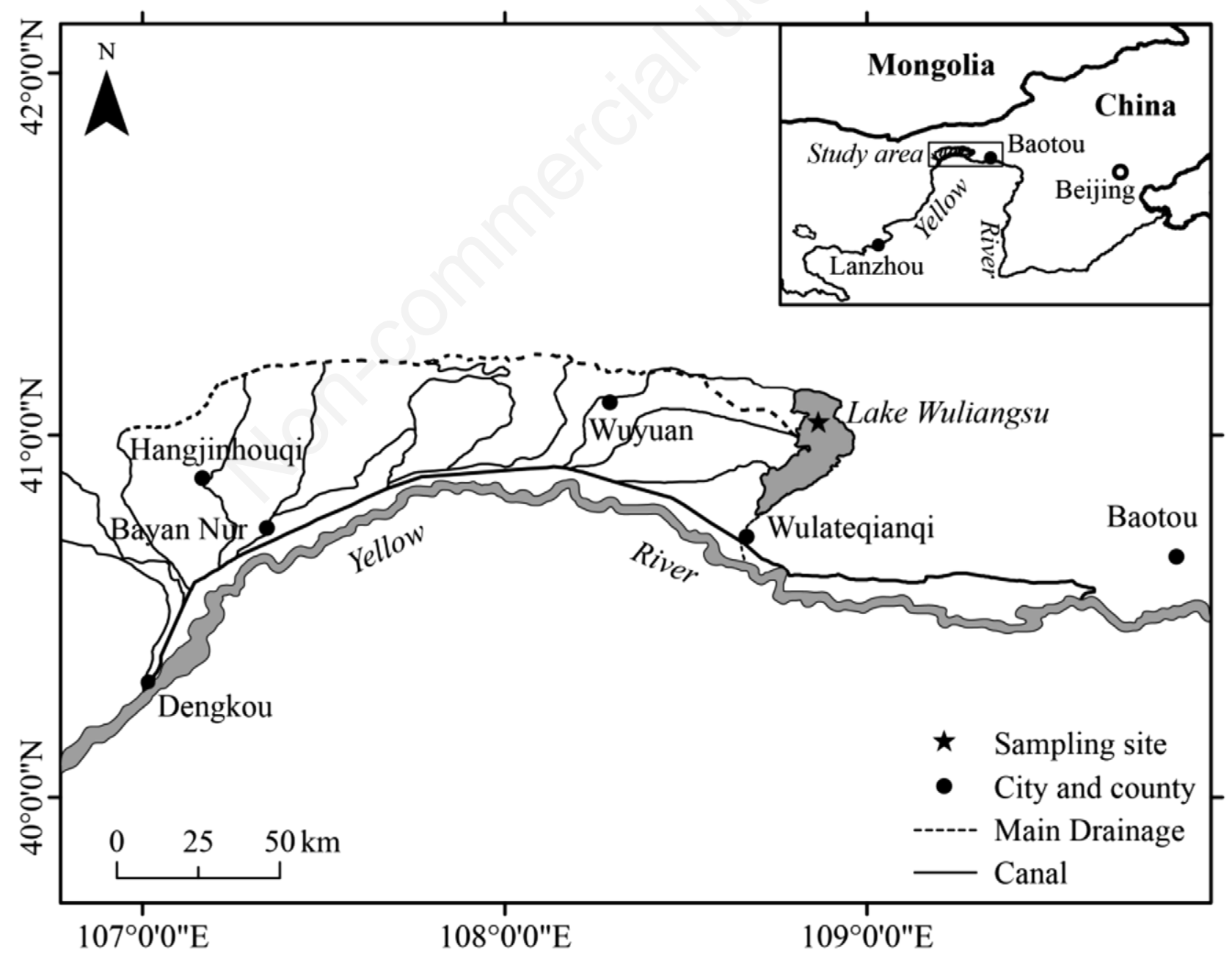

Fig. 1. Sketch map showing the geographic location of Lake Wuliangsu and the core sampling site. 


\section{RESULTS}

The sediment core was dated previously using the decay profile of unsupported ${ }^{210} \mathrm{~Pb}$ activity and the constant rate of supply (CRS) model (Fig. 2) (Wu et al., 2013). The total ${ }^{210} \mathrm{~Pb}$ activity reached equilibrium with supported ${ }^{210} \mathrm{~Pb}$ activity at a depth of $40 \mathrm{~cm}$. Above $40 \mathrm{~cm}$, excess ${ }^{210} \mathrm{~Pb}$ activity $\left({ }^{210} \mathrm{~Pb}_{\mathrm{ex}}\right)$ in the core presented a generally exponential decrease with depth. Total ${ }^{210} \mathrm{~Pb}$ activity in the core declined from $\sim 300 \mathrm{~Bq} \mathrm{~kg}^{-1}$ at the core top to a constant value of about $80 \mathrm{~Bq} \mathrm{~kg}^{-1}$ at $40 \mathrm{~cm}$. The ${ }^{137} \mathrm{Cs}$ peak appeared at $21 \mathrm{~cm}$, signaling the 1963 fallout maximum from atmospheric testing of nuclear weapons (García-Orellana et al., 2006). The ${ }^{210} \mathrm{~Pb}$ dates from the CRS model were in good agreement with dates from the ${ }^{137} \mathrm{Cs}$ record (Fig. 2c) (Wu et al., 2013).

Total PAH concentrations in the sediment core from Lake Wuliangsu ranged from 119 to $568 \mathrm{ng} \mathrm{g}^{-1}$ (Fig. 3). The low molecular weight (LMW) PAHs with 2-3 aromatic rings (Nap, Acy, Ace, Fl, Phe and Ant) ranged from 117 to $501 \mathrm{ng} \mathrm{g}^{-1}$, whereas high molecular weight (HMW) PAHs with 4-6 aromatic rings $(\mathrm{Chr}, \mathrm{BaA}$, Pyr, Flu, BbF, BkF, Bap, DahA, BghiP and IcdP) ranged from $\sim 2$ to 67 $\mathrm{ng} \mathrm{g}^{-1}$. LMW PAHs showed higher proportions among the total 16 PAHs compared to the HMW groups.

PAH concentrations showed a general increase upwards in the core and reached a maximum concentration near the top of the section. Cluster analysis (constrained incremental sum of squares cluster analysis, CONISS) revealed the vertical profile of total PAHs was characterized by three stages: i) prior to the $1950 \mathrm{~s}$; ii) 1950 s to the 1990s; and iii) 1990s to the present (Fig. 3). Prior to the 1950 s, PAH concentrations in sediments were low and constant. The first increase in PAH concentrations was ob- served in the late 1950s. Thereafter, PAH concentrations increased rapidly from the 1990s to the present. The vertical profiles of LMW and HMW PAHs were similar to that of total PAHs, except that HMW PAH values (individual values) increased from almost undetectable at the base of the core (Fig. 3).

The concentrations of DDTs, HCHs, chlordanes, aldrins and endosulfans in the core were in the range of ND-12.3 ng g ${ }^{-1}$, ND-8.4 $\mathrm{ng} \mathrm{g}^{-1}$, ND-8.2 $\mathrm{ng} \mathrm{g}^{-1}$, ND-5.3 ng $\mathrm{g}^{-1}$ and ND-2.6 ng g ${ }^{-1}$, respectively (Fig. 4). Concentrations of OCPs in the core changed only slightly, except in the 1990s. Cluster analysis enabled division of the sedi-

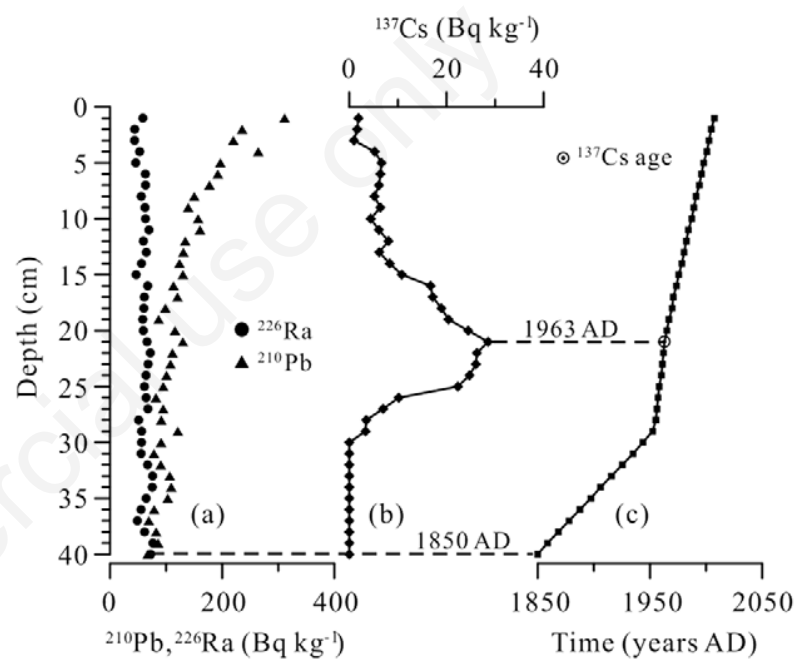

Fig. 2. Age model for the Lake Wuliangsu core. a) ${ }^{210} \mathrm{~Pb}$ and ${ }^{226} \mathrm{Ra}$ activities. b) ${ }^{137} \mathrm{Cs}$ activity. c) Age-depth relation based on ${ }^{210} \mathrm{~Pb}$ and ${ }^{137} \mathrm{Cs}$ dating.

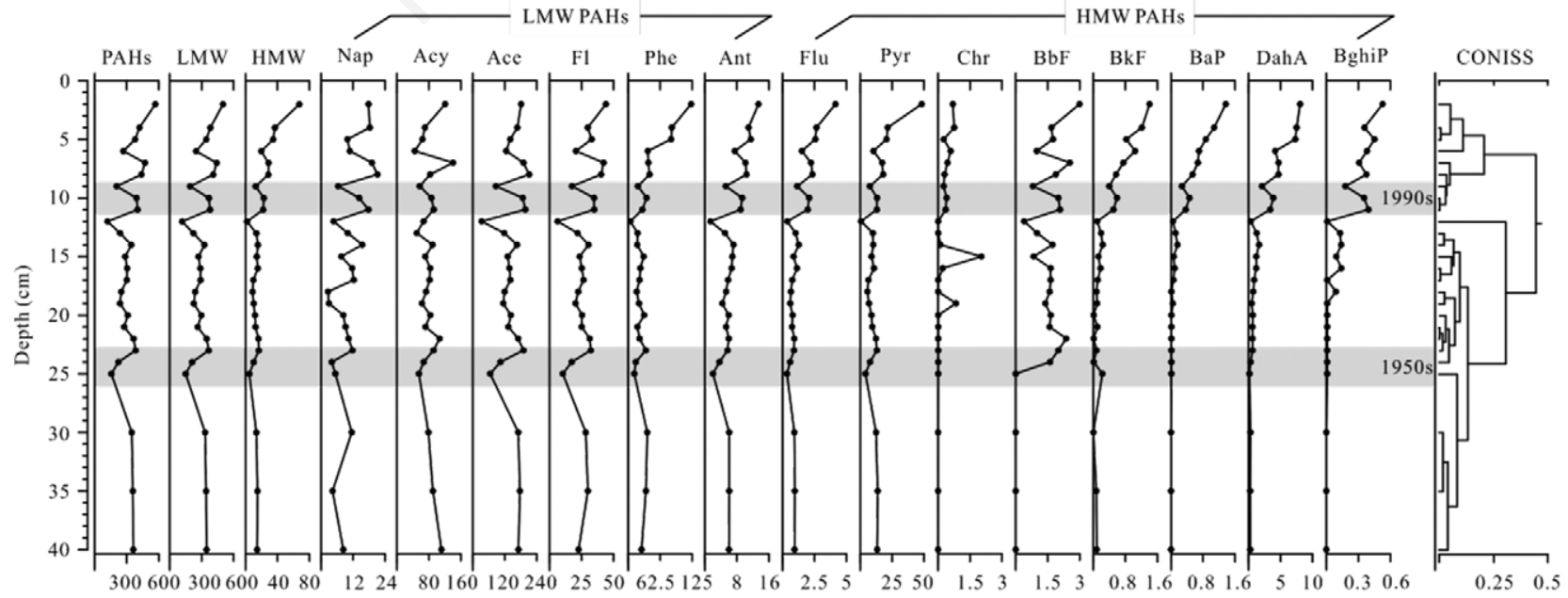

Fig. 3. Concentrations of PAHs $\left(\mathrm{ng}^{-1}\right)$ in the sediment core from Lake Wuliangsu. LMW, LMW PAHs; HMW, HMW PAHs. 
ment OCPs profile into three periods: i) prior to the 1950s; ii) $1950 \mathrm{~s}$ to the $1990 \mathrm{~s}$; and iii) 1990 s to the present (Fig. 4). OCPs were almost undetectable before the 1950s and started to rise in the 1950s. During the 1950s-1990s, there were two high OCP values. After an abrupt rise to the highest value in the 1990s, except that DDT concentrations peaked in the early 2000 s, values declined in the topmost core layers of very recent age. Similar trends are observed for the different OCPs, except that the DDTs peak occurred in the early 2000s.

\section{DISCUSSION}

PAHs in the environment come mainly from anthropogenic sources, e.g., fossil fuel combustion, municipal wastewater discharge and vehicle emissions. PAH composition and distribution are strongly related to the PAH-producing processes. For example, high-temperature combustion processes, such as burning of industrial coal and petroleum fuels, can yield high concentrations of HMW PAHs, whereas petroleum-derived residues and low temperature combustion, such as that of biomass and domestic coal, yield abundant LMW PAH compounds (Yunker and Macdonald, 2003). Anthropogenic PAHs, dominated by the HMW PAHs, markedly increase following industrialization and urbanization due to the close relationship between HMW PAHs emissions and energy consumption (Wilcke, 2007; Guo et al., 2010), which probably reflecting the level of local social-economic development. In contrast, OCPs are mostly used to protect agricultural crops and many high-yield grain fields in China have become areas of high pesticide application (Wang et al., 2005). Therefore, sedimentary changes in PAHs and OCPs reflect the direct influence of anthropogenic activities. HMW PAHs mirror local industrialization and urbanization, whereas LMW PAHs and OCPs correlate with agricultural activities (Yunker and Macdonald, 2003; Guo et al., 2010; Shen et al., 2011; Bigus et al., 2014).

In the late 1950s, LMW PAH and OCP values in the lake sediments started to rise (Figs. 3 and 5), reflecting the onset of large-scale agricultural production practices.

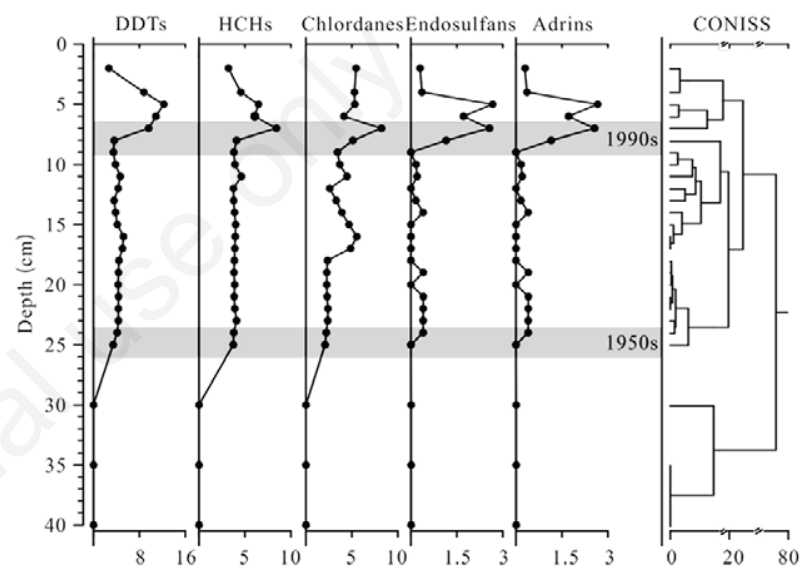

Fig. 4. Distribution of OCPs $\left(\mathrm{ng} \mathrm{g}^{-1}\right)$ in the sediment core from Lake Wuliangsu.

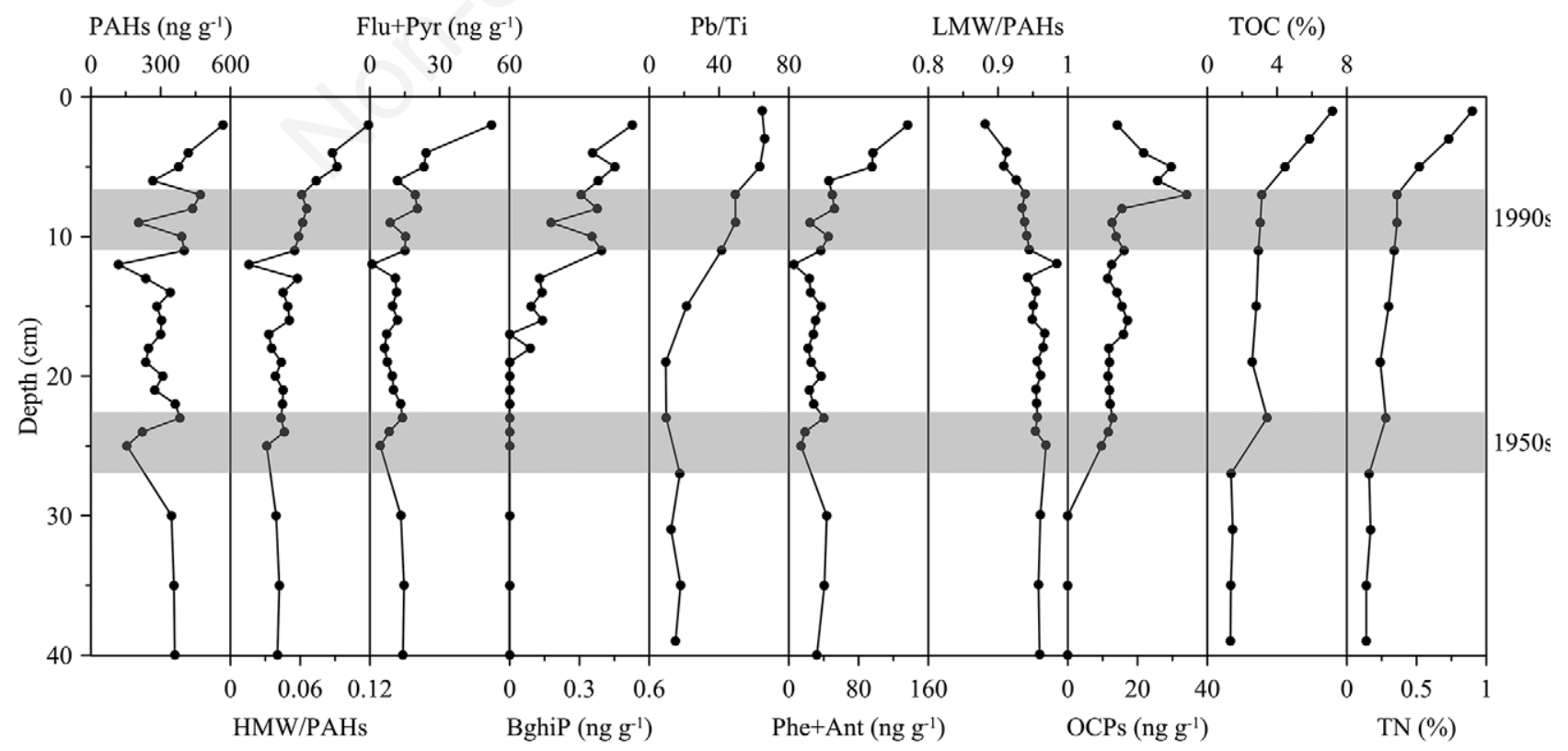

Fig. 5. Distribution of PAHs, DDTs, TOC, $\mathrm{TN}$ and $\mathrm{Pb} / \mathrm{Ti}$ (Ma et al., 2013) in the sediment core from Lake Wuliangsu. 
These included burning of straw indoors for cooking and heating, and burning of fields for fertilizing agricultural soils, both of which contributed enormous quantities of LMW PAHs (Xu et al., 2006). Documents show that the amount of fertilizer given to the Hetao Irrigation District increased from $\sim 70 \times 10^{6} \mathrm{~kg}$ in 1978 to $438 \times 10^{6} \mathrm{~kg}$ in 1997 (Ma et al., 2013). Hydrologic construction projects and catchment reclamation for cultivated field were undertaken after 1950. Consequently, these intensive agricultural activities accelerated the process of eutrophication and shrunk the lake area $\left(\sim 700 \mathrm{~km}^{2}\right.$ in the 1950s and $\sim 220$ $\mathrm{km}^{2}$ in the 1970s) (Ma et al., 2013; Wu et al., 2013; He et al., 2015). In contrast, low values and proportions of HMW PAHs suggested a persistently underdeveloped economy and industry, also inferred from relatively low Flu, Pyr, BghiP and enrichment factors (EFs) for $\mathrm{Pb}$ since Flu and Pyr are tracers of industrial coal, and BghiP and lead were typical markers of vehicle emissions (Harrison et al., 1996; Mai et al., 2003). This result was consistent with the previous study (Ma et al., 2013).

In the 1990s, however, HMW PAHs and their proportions increased in the Lake Wuliangsu sediment, indicating rapid industrialization and urbanization as a consequence of economic growth. Higher Flu, Pyr, BghiP concentrations and $\mathrm{EFs}$ for $\mathrm{Pb}$ provided further evidence. OCP concentrations and proportions of LMW PAHs displayed highest values, but then declined, associated with the implementation of a ban on OCPs and elimination of open burning in China. Increased LMW PAH concentrations in recent years (Fig. 3) resulted from an increase in domestic coal consumption related to rapid urbanization. Higher Ant and Phe values support this inference, as they are indicative of emissions from domestic coal burning (Harison et al., 1996; Mai et al., 2003). Since the 1990s, a large number of small papermaking and other polluting enterprises established in Hetao Irrigation District, prompting local economic and urban development. Meanwhile, these enterprises annually discharged $16 \times 10^{9} \mathrm{~kg}$ of pollutants to Lake Wuliangsu, along with $7 \times 10^{9} \mathrm{~kg} \mathrm{yr}^{-1}$ of domestic sewage (Ma et al., 2013).

PAHs and OCPs in the sediments are valuable proxies for describing the history of human-mediated environmental impact on Lake Wuliangsu. During the last 150 years, the lake experienced two principal periods of human pressure on the environment, the 1950s and 1990s. Therefore, the history of environmental changes in the lake, in response to human activities, can be divided into three stages (Fig. 5). Before the 1950s, PAH concentrations were relatively low, and OCPs were almost undetectable in the sediment, indicating relatively stable environmental conditions with few pollutants. Low nutrient (TOC and TN) concentrations suggested low primary production, i.e. trophic status. At that time, Lake Wuliangsu was a lower-trophic-state lake with little anthro- pogenic impact. During the period from the 1950 s to 1990s, relatively higher OCP values and proportions of LMW PAHs indicated greater agricultural development. Slightly higher TOC and TN values in the sediment suggested the trophic state of the lake increased gradually as a consequence of intensive farming practices. At that time, Lake Wuliangsu became mesotrophic, with increasing agricultural activities in the watershed (Wu et al., 2013). After the 1990s, HMW PAH concentrations and their proportions increased significantly, suggesting rapid industrialization and urbanization. As a result, the lake became eutrophic, as shown by the highest nutrient values. OCP concentrations and proportions of LMW PAHs decreased, indicating the emergence of new agriculture with less application of OCPs and reduced field burning. It is reported that OCPs in this area were phased out of the market gradually in the 1990s, accompanying changes in the production and use of pesticides (Zhang et al., 2010). At that time, Lake Wuliangsu became eutrophic, in association with intensive industrial and urban activities, consistent with results from a previous study and lake monitoring data (Wu et al., 2013).

Historical changes in the types of anthropogenic activities recorded by PAHs and OCPs in the sediment core were compared with local socioeconomic data (Statistical Bureau of Inner Mongolia Autonomous Region, 2009). Energy consumption and urban population numbers indicate slow economic growth and low levels of industrialization and urbanization during the period 1950-1990 (Fig. 6), with the largest share of the gross domestic product (GDP) probably from agriculture before 1990. Since then, industrialization and urbanization developed rapidly, along with economic growth. LMW PAHs and OCPs in Lake Wuliangsu were relatively higher in the late 1950s. Then in the 1990s, HMW PAH values and their propor-

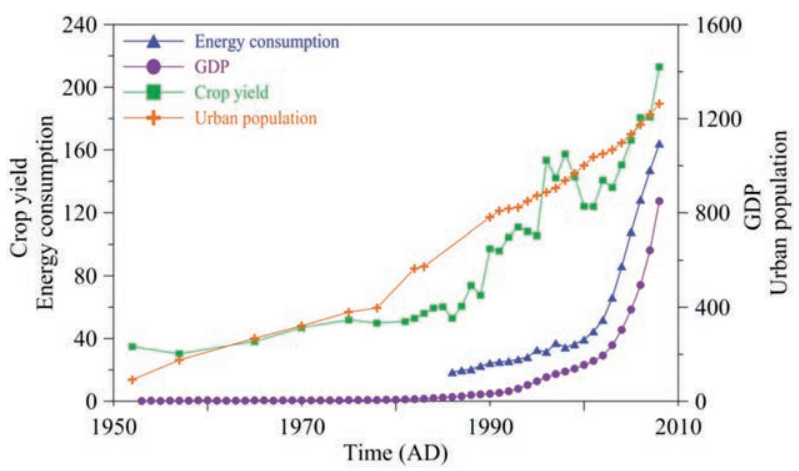

Fig. 6. Energy consumption (million tons), GDP (billion RMB), crop yield (10 thousand tons) and urban population (10 thousand people) of the Inner Mongolia Autonomous Region in last $\sim 60$ years (Statistical Bureau of Inner Mongolia Autonomous Region, 2009). 
tions increased at a rapid pace, whereas OCP values and proportions of LMW PAHs declined. It is therefore clear that HMW PAHs records correspond to local industrial and urban development, whereas LMW PAH and OCP profiles correspond to agricultural activities. A rapid increase in HMW PAHs and peak inputs of OCPs in Lake Wuliangsu, in the 1990s, occurred some 10 years later than in developed regions of China, e.g., the Pearl River Delta of South China, and Lake Taihu in East China (Zhang et al., 2002; Liu et al., 2005; Liu et al., 2009). Thus, the period of rapid economic growth in the Lake Wuliangsu catchment lagged behind that in these other regions (National Bureau of Statistics of China, 2009). Sedimentary records of PAHs and OCPs in China also differ from those reported in developed countries, e.g., the United States, Japan and Europe. In these countries, industrialization and urbanization was complete and they had banned OCPs in agriculture before the 1980s, resulting in a PAH peak in the 1950s-1980s and an OCP peak in the 1960s-1970s, respectively (Santschi et al., 2001; Shimizu et al., 2005; Götz et al., 2007; Ishitake et al., 2007). Rapid development in China lagged behind these countries, such that the period during which PAHs started to decrease in developed countries corresponds to the time when PAHs has just started to increase rapidly in China. The ban on OCP use in developed countries occurred some 10 years earlier than the ban in China. The different patterns in sedimentary records of PAHs and OCPs among regions of the world parallel the different histories of industrial, urban and agricultural development. Overall, the $\mathrm{PAH}$ and OCP stratigraphies in the sediments from Lake Wuliangsu provide reliable records of human-mediated impacts on environmental changes in the Yellow River Basin over the past $\sim 150$ years.

\section{CONCLUSIONS}

OCP and PAH concentrations in the sediments of Lake Wuliangsu are useful indicators of human-driven environmental changes in the basin over the past $\sim 150$ years. Anthropogenic sources for HMW PAHs are mainly from industrial and urban development processes, whereas LMW PAHs and OCPs are produced largely by agricultural activities. Shifts in human activities recorded by the PAH and OCP profiles can be divided into three time periods. The earliest period, representing sediment deposited before the 1950s, is indicative of a fairly stable environment with minimal human impact, accompanied by low pollutant and nutrient concentrations. With agricultural development in the 1950s, the lake trophic state increased. The most recent phase in the history of Lake Wuliangsu started in the 1990s and is marked by intensive industrial and urban activities, which coincide with eutrophication. The history of human activities corresponds well with local socio-economic data inferred from comparison of PAH and OCP records in different regions of the world. Sedimentary PAHs and OCPs from Lake Wuliangsu provide specific information regarding past human impacts on environmental conditions.

\section{ACKNOWLEDGMENTS}

We thank Jin Miao, Zeng Haiao and Ma Long for laboratory assistance. Thanks are also due to Mark Brenner for his valuable suggestions and revision of the text and the journal reviewers for their helpful comments and suggestions that improved the manuscript. This study was supported by NSFC (41671200; 41373017; U1138301).

\section{REFERENCES}

Bigus P, Tobiszewski M, Namieśnik J, 2014. Historical records of organic pollutants in sediment cores. Mar. Pollut. Bull. 78:26-42.

García-Orellana J, Sánchez-Cabeza JA, Masqué P, Àvila A, Costa E, Loÿe-Pilot MD, Bruach-Menchén JM, 2006. Atmospheric fluxes of ${ }^{210} \mathrm{~Pb}$ to the western Mediterranean Sea and the Saharan dust influence. J. Geophys. Res. 111:D15305.

Götz R, Bauer O-H, Friesel P, Herrmann T, Jantzen E, Kutzke M, Lauer R, Paepke O, Roch K, Rohweder U, Schwartz R, Sievers S, Stachel B, 2007. Vertical profile of PCDD/Fs, dioxin-like PCBs, other PCBs, PAHs, chlorobenzenes, DDX, HCHs, organotin compounds and chlorinated ethers in dated sediment/soil cores from flood-plains of the river Elbe, Germany. Chemosphere 67:592-603.

Guo J, Wu F, Luo X, Liang Z, Liao H, Zhang R, Li W, Zhao X, Chen S, Mai B, 2010. Anthropogenic input of polycyclic aromatic hydrocarbons into five lakes in Western China. Environ. Pollut. 158: 2175-2180.

Machado KS, Figueira RC, Côcco LC, Froehner S, Fernandes CV, Ferreira PA, 2014. Sedimentary record of PAHs in the Barigui River and its relation to the socioeconomic development of Curitiba, Brazil. Sci. Total Environ. 482: 2-52.

Hammer Ø, Harper DAT, Ryan PD, 2001. Past: palaeontological statistics software package for education and data analysis. Palaeontol. Electron. 4:1-9.

Harrison RM, Smith DJT, Luhana L, 1996. Source apportionment of atmospheric polycyclic aromatic hydrocarbons collected from an urban location in Birmingham, U.K. Environ. Sci. Technol. 30:825-832.

He Y, Sun D, Wu J, Sun Y, 2015. Factors controlling the past $\sim 150$-year ecological dynamics of Lake Wuliangsu in the upper reaches of the Yellow River. Holocene 25:1394-1401.

Ishitake M, Moriwaki H, Katahira K, Yamamoto O, Tsuruho K, Yamazaki H, Yoshikawa S, 2007. Vertical profile of polycyclic aromatic hydrocarbons in a sediment core from a reservoir in Osaka City. Environ. Geol. 52:123-129.

Kim KH, Jahan SA, Kabir E, Brown RJ, 2013. A review of airborne polycyclic aromatic hydrocarbons (PAHs) and their human health effects. Environ. Int. 60:71-80.

Liu GQ, Zhang G, Li XD, Li J, Peng XZ, Qi SH, 2005. Sedi- 
mentary record of polycyclic aromatic hydrocarbons in a sediment core from the Pearl River Estuary, South China. Mar. Pollut. Bull. 51:912-921.

Liu G, Zhang G, Jin Z, Li J, 2009. Sedimentary record of hydrophobic organic compounds in relation to regional economic development: a study of Taihu Lake, East China. Environ. Pollut. 157:2994-3000.

Liu Y, Yu N, Li Z, Wei Y, Ma L, Zhao J, 2012. Sedimentary record of PAHs in the Liangtan River and its relation to socioeconomic development of Chongqing, Southwest China. Chemosphere 89:893-899.

Lü C, He J, Sun H, Xue H, Liang Y, Bai S, Sun Y, Shen L, Fan Q, 2008. Application of allochthonous organic carbon and phosphorus forms in the interpretation of past environmental conditions. Environ. Geol. 55:1279-1289.

Ma L, Wu J, Abuduwaili J, 2013. Geochemical evidence of the anthropogenic alteration of element composition in lacustrine sediments from Wuliangsu Lake, north China. Quatern. Int. 306:107-113.

Mai BX, Qi SH, Zeng EY, Yang QS, Zhang G, Fu JM, Sheng GY, Peng PA, Wang ZS, 2003. Distribution of polycyclic aromatic hydrocarbons in the coastal region off Macao, China: assessment of input sources and transport pathways using compositional analysis. Environ. Sci. Technol. 37:4855-4863.

National Bureau of Statistics of China, 2009. [China Statistical Yearbook 2009].[Book in Chinese]. China Statistics Press, Beijing.

Santschi PH, Presley BJ, Wade TL, Garcia-Romero B, Baskaran M, 2001. History contamination of PAHs, PCBs, DDTs, and heavy metals in Mississippi River Delta, Galveston Bay and Tampa Bay Sediment cores. Mar. Environ. Res. 52:51-79.

Schmid P, Bogdal C, Blüthgen N, Anselmetti FS, Zwyssig A, Hungerbuhler K, 2010. The missing piece: sediment records in remote mountain lakes confirm glaciers being secondary sources of persistent organic pollutants. Environ. Sci. Technol. 45:203-208.
Shen G, Wang W, Yang Y, Ding J, Xue M, Min Y, Zhu C, Shen H, Li W, Wang B, Wang R, Wang X, Tao S, Russell AG, 2011. Emissions of PAHs from indoor crop residue burning in a typical rural stove: emission factors, size distributions, and gas-particle partitioning. Environ. Sci. Technol. 45: 1206-1212.

Shimizu J, Yamao S, Nosaka T, Noguchi KI, Mine M, Matsumoto K, Oichi K, Tsutsumi K, Miyamoto T, Ikeda Y, 2005. Distributions of sedimentary POPs (persistent organic pollutants) in Tokyo Bay-results from the survey of POPs in Tokyo Bay in 2002. Rep. Hydrogr. Oceanogr. Res. 41:35-50.

Statistical Bureau of Inner Mongolia Autonomous Region, 2009. [Statistical Yearbook of Inner Mongolia].[Book in Chinese]. China Statistics Press, Beijing.

Wang T, Lu Y, Zhang H, Shi Y, 2005. Contamination of persistent organic pollutants (POPs) and relevant management in China. Environ. Int. 31:813-821.

Wu J, Ma L, Yu H, Zeng H, Liu W, Abuduwaili J, 2013. Sediment geochemical records of environmental change in Lake Wuliangsu, Yellow River Basin, north China. J. Paleolimnol. 50:245-255.

Wilcke W, 2007. Global patterns of polycyclic aromatic hydrocarbons (PAHs) in soil. Geoderma 141:157-166.

Xu S, Liu W, Tao S, 2006. Emission of polycyclic aromatic hydrocarbons in China. Environ. Sci. Technol. 40:702-708.

Yunker MB, Macdonald RW, 2003. Alkane and PAH depositional history, sources and fluxes in sediments from the Fraser River Basin and Strait of Georgia, Canada. Org. Geochem. 34:1429-1454.

Zhang G, Parker A, House A, Mai B, Li X, Kang Y, Wang Z, 2002. Sedimentary records of DDT and HCH in the Pearl River Delta, south China. Environ. Sci. Technol. 36:36713677.

Zhang Y, Li C, Pei G, Shi X, 2010. [Necessity of research on OCPs in the Wuliangsuhai Lake].[in Chinese]. POPs Forum 2010. 